Article

\title{
Analysing the Effect of Substrate Properties on Building Envelope Thermal Performance in Various Climates
}

\author{
Kishor T. Zingre ${ }^{1, *}$, Kiran Kumar D. E. V. S. ${ }^{2}$ and Man Pun Wan ${ }^{2}$ \\ 1 Department of Architecture and Built Environment, Northumbria University, Newcastle NE1 8ST, UK \\ 2 School of Mechanical and Aerospace Engineering, Nanyang Technological University, \\ Singapore 639798, Singapore; kirankumar.devs@gmail.com (K.K.D.E.V.S.); mpwan@ntu.edu.sg (M.P.W.) \\ * Correspondence: kishor.zingre@northumbria.ac.uk
}

Received: 22 February 2020; Accepted: 9 September 2020; Published: 1 October 2020

\begin{abstract}
Existing regulations on the thermal efficiency of building envelope assemblies are based on the steady state thermal properties of substrate materials. Heat transfer mechanisms of passive heat curbing methods such as phase change materials and cool materials, which are dynamic in nature, are currently not being accounted for. The effectiveness of thermo-physical and solar radiation properties of building materials (i.e., solid homogeneous layers without air gap) in reducing the heat gain into a building in a hot climate could be well understood with the equivalent thermal resistance $\left(R_{\text {eq }}\right)$ concept. A simple and easy-to-use mathematical derivation (i.e., to estimate the instantaneous heat flux across an envelope assembly) is proposed in this paper to understand the mechanism of equivalent R-value (i.e., reciprocal of thermal transmittance, U-value) due to solar radiation properties of passive substrate materials. The model is validated against field experiments carried out at two apartment units of a residential building. The $R_{e q}$ due to high outer surface solar radiation properties (i.e., by applying a cool coating) is dynamic as it varies with the weather conditions. The effect of a substrate material's solar radiation and thermo-physical properties on the overall roof thermal performance is investigated using the $R_{e q}$ model for four cooling dominated climates around the globe, having different diurnal conditions and sky temperatures. Increasing the outer surface's solar reflectance (from $10 \%$ to $80 \%$ ) reduces net heat gain through the flat roof during both daytime and nighttime. In contrast, adding only thermal resistance (from $5 \mathrm{~mm}$ to $75 \mathrm{~mm}$ thick polyurethane) or volumetric heat capacity (by adding $5 \mathrm{~mm}$ thick phase change material) to the building envelope brings down heat gain during the day, but not in the night. Thermal insulation is found to be the second effective property, followed by thermal mass irrespective of different diurnal conditions and sky temperatures across the climates.
\end{abstract}

Keywords: E-equivalent R-value; passive cooling; substrate materials; building envelope; thermal performance

\section{Introduction}

Solar irradiation incidents on an opaque envelope (roof and walls) assembly are partially reflected and the remaining are absorbed at the outdoor exposed surface. Some of the generated heat (due to absorbed solar radiation) is stored in the envelope assembly, while the remaining is conducted into the building's indoor environment, leading to gained heat discomfort for the occupants and increased cooling load for the air-conditioning system. The heat gain in the indoor environment could be reduced by employing passive strategies such as, (i) reducing the solar absorptance of outdoor exposed envelope assembly surface by enhancing solar radiation properties, (ii) adding thermal insulation 
to curb the inward heat transfer by conduction, (iii) adding thermal mass to enhance the storage of generated heat (during the daytime) in the outdoor exposed surface and later releasing it back to the outdoor environment (during the nighttime). These three strategies could be achieved, e.g., (i) by applying a cool coating/material on the outdoor exposed envelope surface [1,2], (ii) by topping up a layer of insulation [3], or (iii) by adding heavy construction materials or phase-change materials [4-8]. Due to the high intensity of incident irradiation, these three strategies are of utmost importance in tropical climates such as that of Singapore.

Cool coatings [8,9] are considered to have high solar radiation properties which help to reflect the solar irradiation in the daytime and re-emit the absorbed heat to the outdoors during the night-time. Over the years, several studies have been performed on cool coatings, and it has been found that their thermal performance is effective in reducing heat gain, and this behaviour is a function of local climate conditions [9]. This infers that cool coating essentially enhances the R-value of the substrate material by reducing the overall heat gain. Therefore, it can be hypothesized that the cool coating provides additional equivalent $\mathrm{R}$-value to the substrate material, which varies with the weather conditions. Equivalent R-value $\left(R_{e q}\right)$ is therefore a conceptual representation of the enhanced thermal resistance that equates to the same thermal performance of an insulation material as a non-conductive effect, under a set of test conditions. In our case, the effect of an increase in thermal resistance is due to the enhanced surface solar radiation properties.

$\mathrm{R}$-value, which is defined concerning steady-state conditions, may not be a single determining factor for envelope thermal performance, especially in locations where solar gains and diurnal temperature variation is high $[3,9,10]$. There are several methods and systems available to determine the dynamic thermal performance of envelope systems. Kosney et al. [11] evaluated the thermal performance of various massive and insulated wall systems using dynamic energy simulations for different climates and proposed a dimensionless multiplier called Dynamic Benefit of Massive Systems (DBMS). They estimated this multiplier for R-value that is needed in light buildings to produce the same energy demand as massive buildings (Equivalent R-value for massive systems). Long et al. [12] simulated building envelope materials having different combinations of thermal conductivity and volumetric heat capacity and presented the results in terms of energy performance. These studies, despite stating the advantages of thermal mass in the building envelope, did not account for the additional benefits of surface radiation property concerning the substrate material. Muscio et al. [13] developed a "solar transmittance index" (STI) taking into account both the radiative properties and the thermo-physical properties of the substrate materials. Al Sanea et al. [1] studied the concept of critical thermal mass thickness along with the effect of surface absorptivity by evaluating yearly averaged dynamic R-values. These methods however, lack experimental proof and require certain assumptions for surface heat transfer coefficients.

Therefore, in this paper, easy-to-use numerical expressions are derived that can be used to evaluate the dynamic thermal behaviour of enhanced solar radiation properties when a cool coating is applied to an outdoor exposed surface of a building roof assembly. The previously developed and experimentally validated heat transfer model was used for developing the formulations. The proposed expression $K_{\rho}^{C R H T}$ is validated using field measurements carried out at two unoccupied apartment units of a high-rise residential building located in Singapore.

\section{Methodology}

This study consists of parametric analyses using the proposed heat transfer model $[14,15]$ for estimating envelope heat gain reduction. Field experiments (to measure irradiation, weather parameters, radiation properties and temperatures of roof and ceiling surfaces) were performed at two side-by-side, unoccupied apartments located on the top floor of a high-rise building located in Singapore, as shown in Figure 1. The rooftop of one apartment was a cool roof $(\rho=80 \%)$ and the second one was a bare concrete roof $(\rho=10 \%)$. The roof assembly was comprised of a (from exterior to interior) concrete slab (110 mm thickness) and cement plaster (15 $\mathrm{mm}$ thickness). To develop numerical expressions for 
the proposed heat transfer model, inputs of, (i) solar-air temperature and (ii) exterior/interior surface heat transfer coefficients, were needed. These input details along with the other properties (thermal and solar radiation) of the building materials and climate inputs could be referred from [15].

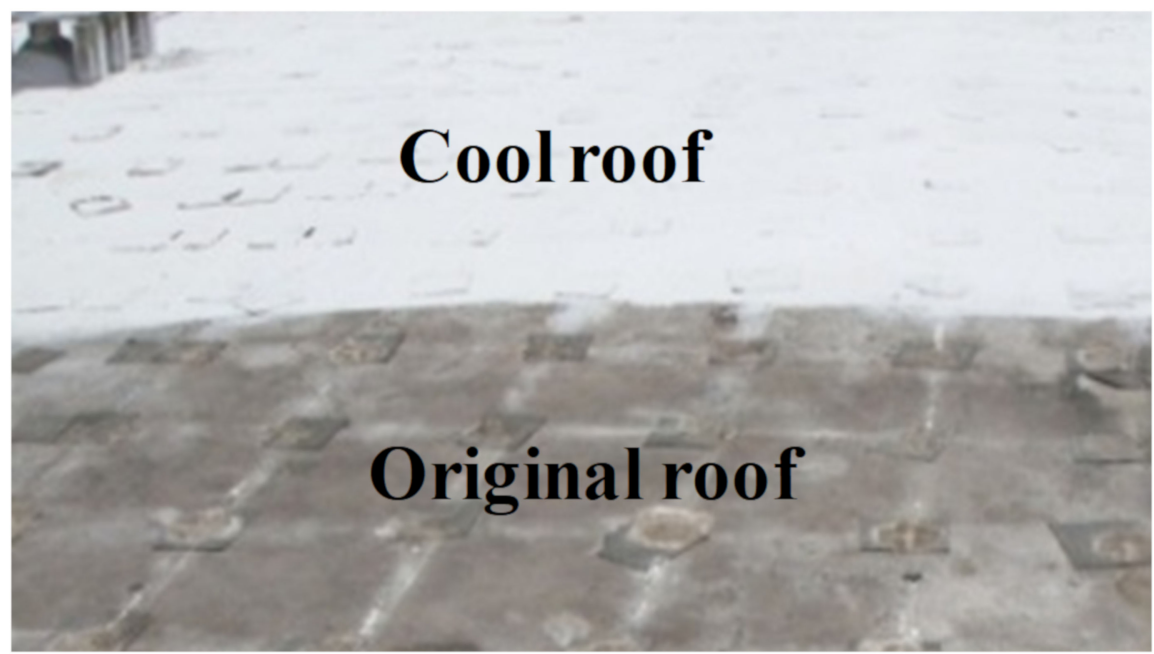

Figure 1. Experimental roof of a residential building in Singapore.

The solar irradiation was measured on the rooftop of the apartment using a pyranometer. The average-daily insolation on a typical cloudy day and a sunny day was measured as $3698 \mathrm{~W}-\mathrm{h} / \mathrm{m}^{2}$ and $6137 \mathrm{~W}-\mathrm{h} / \mathrm{m}^{2}$ respectively. Mean hourly surface heat transfer coefficients were estimated for both the apartment rooftops using the on-site measured data. Detailed formulations for the estimation of overall heat transfer coefficients can be found in [16]. Solar radiation properties of the rooftop surfaces i.e., solar reflectance were measured using a portable solar spectrum reflectometer (Devices and Services, SSR-6), whereas thermal emittance using a portable emissometer (Devices and Services, AE1-RD1).

\section{Results and Discussion}

This section elaborates the impact of cool coating along with that of thermal resistance and volumetric heat capacity of the substrate material using the proposed heat transfer model. The proposed $K_{\rho}^{C R H T}$ expression would be used to deliberate the impacts on a base case roof $(\rho=10 \%)$ under different climate conditions by (i) applying cool coating (that increases $\rho$ from $10 \%$ to $80 \%$ ), (ii) topping up the insulation layer (that increases $R$ ) and (iii) adding thermal mass (that increases heat capacity).

\subsection{Validating the Model for Equivalent Thermal Resistance}

The proposed mathematical expression for equivalent thermal resistance was derived based on the Cool Roof Heat Transfer model which was validated using the experimental measurements of roof and ceiling surface temperatures and heat flux through the roof slab as discussed in [15]. The cool coating that was used for validation had a thickness of $0.5 \mathrm{~mm}$ and solar radiation properties i.e., solar reflectance of $30 \%$ and thermal emittance of $84 \%$. The model was validated using the experimental data obtained over a period of a month which included sunny and cloudy days in the hot and humid climate of Singapore.

\subsection{Daily Performance of Different Roof Substrate Properties}

Table 1 summarizes the estimated effect of varying $C_{v}, R$ and $\rho$ on integrated daily heat gain/loss through the rooftop section in Singapore's climate. For a typical sunny day, increasing $C_{v}$ of the substrate results in about $8 \%$ reduction in daily heat gain whereas that effect is up to $68 \%$ by applying a cool coating on the exterior surface and up to $82 \%$ by increasing $R$ of the substrate. The results suggest that 
increasing heat capacity to the roof is ineffective in curbing the daily heat gain compared to adding a layer of thermal insulation or by increasing the exterior surface reflectance. It can also be noticed that the effect of $C_{v}$ further diminishes with the rise in $R$ of the roof substrate material.

Table 1. Effects of thermo-physical and solar radiation properties on daily heat flux performance in a tropical climate.

\begin{tabular}{ccccc}
\hline \multirow{2}{*}{ Parameter } & \multicolumn{2}{c}{ Daily Heat Gain } & \multicolumn{2}{c}{ Daily Heat Loss } \\
\cline { 2 - 5 } & Sunny Day & Cloudy Day & Sunny Day & Cloudy Day \\
\hline $\begin{array}{c}\text { Increasing } \rho \text { only } \\
\text { (from } 10 \% \text { to } 80 \%)\end{array}$ & $-68 \%$ & $-60 \%$ & $+50 \%$ & $+43 \%$ \\
\hline $\begin{array}{c}\text { Increasing } C_{v} \text { only } \\
\left.\text { from } 500 \text { to } 5000 \mathrm{~kJ} / \mathrm{m}^{3}-\mathrm{K}\right)\end{array}$ & $-8 \%$ & $-1 \%$ & $-100 \%$ & $-100 \%$ \\
\hline $\begin{array}{c}\text { Increasing } R \text { only } \\
\left.\text { (from } 0.25 \text { to } 1.50 \mathrm{~m}^{2}-\mathrm{K} / \mathrm{W}\right)\end{array}$ & $-82 \%$ & $-80 \%$ & $-50 \%$ & $-60 \%$ \\
\hline
\end{tabular}

Baseline original roof: $R=0.25 \mathrm{~m}^{2}-\mathrm{K} / \mathrm{W}, C_{\mathrm{v}}=500 \mathrm{~kJ} / \mathrm{m}^{3}-\mathrm{K}$ and $\rho=10 \%$.

\subsection{Annual Performance of Different Roof Substrate Properties}

Further, a typical metrological year of weather data of Singapore [16] was used to assess heat gain on an annual basis. The hourly solar-air temperature data is estimated using the detailed model given in [17]. For roofs with the range of $R$ (shown in Figure 2), an increase in thermal mass $\left(C_{v}\right)$ results in a minimal $(<5 \%)$ drop in annual heat gain, compared to that attained by increasing surface reflectance $(\rho)$ or thermal resistance $(R)$, which is around $60-80 \%$. Considering a light metal roof (with $5 \mathrm{~mm}$ polyurethane insulation) with $R$ of $0.25 \mathrm{~m}^{2}-\mathrm{K} / \mathrm{W}$ and $C_{v}$ of $500 \mathrm{~kJ} / \mathrm{m}^{3}-\mathrm{K}$ as the base case, increasing $R$ up to $0.75 \mathrm{~m}^{2}-\mathrm{K} / \mathrm{W}$ (e.g., $20 \mathrm{~mm}$ thick Polyurethane insulation) reduces the annual heat gain by up to $66 \%$. Whereas when an increase in $\rho$ (from $10 \%$ to $80 \%$ ) is present, annual heat gain reduces by $78 \%$. Increasing $C_{v}$ up to $5000 \mathrm{~kJ} / \mathrm{m}^{3}-\mathrm{K}$ (e.g., a $5 \mathrm{~mm}$ thick layer of PCM embedded cement mortar), the annual heat gain reduces insignificantly $(2 \%)$. This suggests that almost all the heat reduction by cool coating is achieved due to the reflection of the solar radiation/sky cooling of the roof during night time. Similarly, increasing $C_{v}$ from 500 to $5000 \mathrm{~kJ} / \mathrm{m}^{3}-\mathrm{K}$ brings a very minor effect on the $R_{e q}$ of the cool roof.

The estimated impact of $R, C_{v}$ and $\rho$ on annual heat gain and $R_{e q}$ of roofs for a tropical climate is illustrated in color gradient plots in Figure 2. Some common roof construction materials (shown in Table 2) are highlighted in these plots. It is clear from the figure that annual heat gain reduction with an increase in $\rho$ is significant for the low- $R$ roofs (i.e., $0.25 \mathrm{~m}^{2}-\mathrm{K} / \mathrm{W}$ ), whereas the effect decreases as $R$ increases. Also, the increase in $C_{v}$ has a much lower impact in minimizing annual heat gain. Figure 2 also illustrates that the impact of applying the cool coating is inversely proportional to the $\rho$ of the base case roof. Thus, applying cool coating on a conventional roof with low $\rho$ is effective, whereas adding insulation and increasing $R$-value has a significant effect on highly reflective roofs. This contour graph can be used as a reference in general for roofs with an R-value between 0.25 and $1.50 \mathrm{~m}^{2}-\mathrm{K} / \mathrm{W}$ with any volumetric heat capacity $<5000 \mathrm{~kJ} / \mathrm{m}^{3}-\mathrm{K}$ and reflectance between $10 \%$ and $80 \%$ while predicting the effect on annual heat gain and $R_{e q}$ in a tropical climate. 


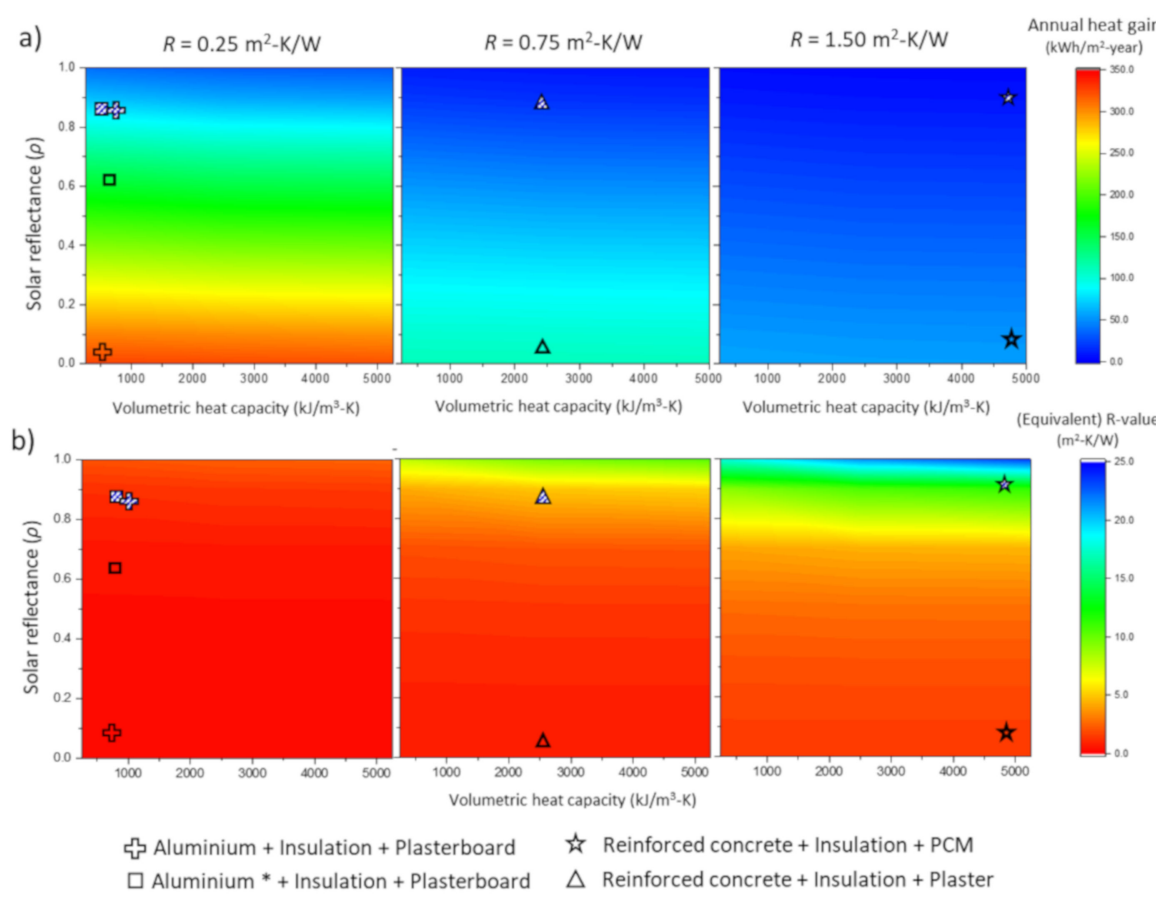

Figure 2. Effects of thermo-physical and solar radiation properties on (a) annual heat gain and (b) $R_{e q}$-value for common roof construction materials (filled pattern represents roof assemblies with a cool coating $(\rho=80 \%)$ and without pattern represents roof assemblies without cool coating $(\rho=10 \%)$ ).

Table 2. Thermo-physical properties of common roof construction materials.

\begin{tabular}{|c|c|c|c|c|c|c|}
\hline \multirow{2}{*}{ No. } & \multicolumn{3}{|c|}{ Roof Assembly Layers } & \multirow{2}{*}{$\begin{array}{c}R \\
\left(\mathrm{~m}^{2}-\mathrm{K} / \mathrm{W}\right)\end{array}$} & \multirow{2}{*}{$\begin{array}{c}\rho \text { of Outside Exposed } \\
\text { Surface (\%) }\end{array}$} & \multirow{2}{*}{$\begin{array}{c}C_{v} \\
\left(\mathrm{~kJ} / \mathrm{m}^{3}-\mathrm{K}\right)\end{array}$} \\
\hline & Outside Layer & Middle Layer & Inside Layer & & & \\
\hline 1 & $\begin{array}{l}\text { Aluminum } \\
(5 \mathrm{~mm})\end{array}$ & $\begin{array}{l}\text { Polyurethane } \\
\text { (5 mm) }\end{array}$ & $\begin{array}{l}\text { Plasterboard } \\
(20 \mathrm{~mm})\end{array}$ & 0.25 & 10 & 500 \\
\hline 2 & $\begin{array}{l}\text { Aluminum } \\
(5 \mathrm{~mm})\end{array}$ & $\begin{array}{l}\text { Polyurethane } \\
(5 \mathrm{~mm})\end{array}$ & $\begin{array}{l}\text { Plasterboard } \\
(20 \mathrm{~mm})\end{array}$ & 0.25 & 60 & 500 \\
\hline 3 & $\begin{array}{l}\text { Reinforced concrete } \\
\qquad(100 \mathrm{~mm})\end{array}$ & $\begin{array}{l}\text { Polyurethane } \\
\quad(20 \mathrm{~mm})\end{array}$ & $\begin{array}{l}\text { Plaster } \\
(15 \mathrm{~mm})\end{array}$ & 0.75 & 10 & 2300 \\
\hline 4 & $\begin{array}{l}\text { Reinforced concrete } \\
\quad(100 \mathrm{~mm})\end{array}$ & $\begin{array}{l}\text { Polyurethane } \\
\text { (75 mm) }\end{array}$ & $\begin{array}{l}\text { PCM } \\
(5 \mathrm{~mm})\end{array}$ & 1.50 & 10 & 5000 \\
\hline
\end{tabular}

Thermal conductivity of polyurethane $=0.08 \mathrm{~W} / \mathrm{m}-\mathrm{K}$, thermal conductivity of reinforced concrete $=0.3 \mathrm{~W} / \mathrm{m}-\mathrm{K}$, thermal conductivity of aluminum $=12.5 \mathrm{~W} / \mathrm{m}-\mathrm{K}$, thermal conductivity of plasterboard $=0.6 \mathrm{~W} / \mathrm{m}-\mathrm{K}$.

\subsection{Substrate Performance in Various Climates}

The predicted heat gain reduction due to different $R, C_{v}$ and $\rho$ values are further investigated in three other climate zones, namely Athens (Mediterranean subtropical climate), Abu Dhabi (Hot desert climate), New Delhi (Composite climate) and compared with results of Singapore (hot and humid tropical climate). The input data used for these calculations are summarized in Table 3. Figure 3 shows a reduction in annual heat gain and an increase in $R_{e q}$ with varying $R, C_{v}$ and $\rho$ properties of the substrate material. The effect of increasing only $R$ of the roof material (from 0.25 to $1.5 \mathrm{~m}^{2}-\mathrm{K} / \mathrm{W}$ ) on annual heat gain reduction for the base case roof is almost the same (82-83\%) across all the four climates. Whereas, the effect of increasing $C_{v}$ (from $500 \mathrm{~kJ} / \mathrm{m}^{3} \mathrm{~K}$ to $5000 \mathrm{~kJ} / \mathrm{m}^{3} \mathrm{~K}$ ) on the reduction of annual heat gain in the case of Athens is much higher (over $22 \%$ ) compared to $2-4 \%$ in the other three climates. At the same time, the effect of increasing only $\rho$ (i.e., from $10 \%$ to $80 \%$ or grey to cool) on reduction in annual heat gain is the highest in the case of Athens $(96 \%)$ and in the range $73-78 \%$ for the other three climates. The prominent effect of enhanced $C_{v}$ and $\rho$ in Athens could be due to 
the overall effect of considerably low annual-average outdoor air temperature and sky temperature as compared to that in the other three climates (shown in Table 2).

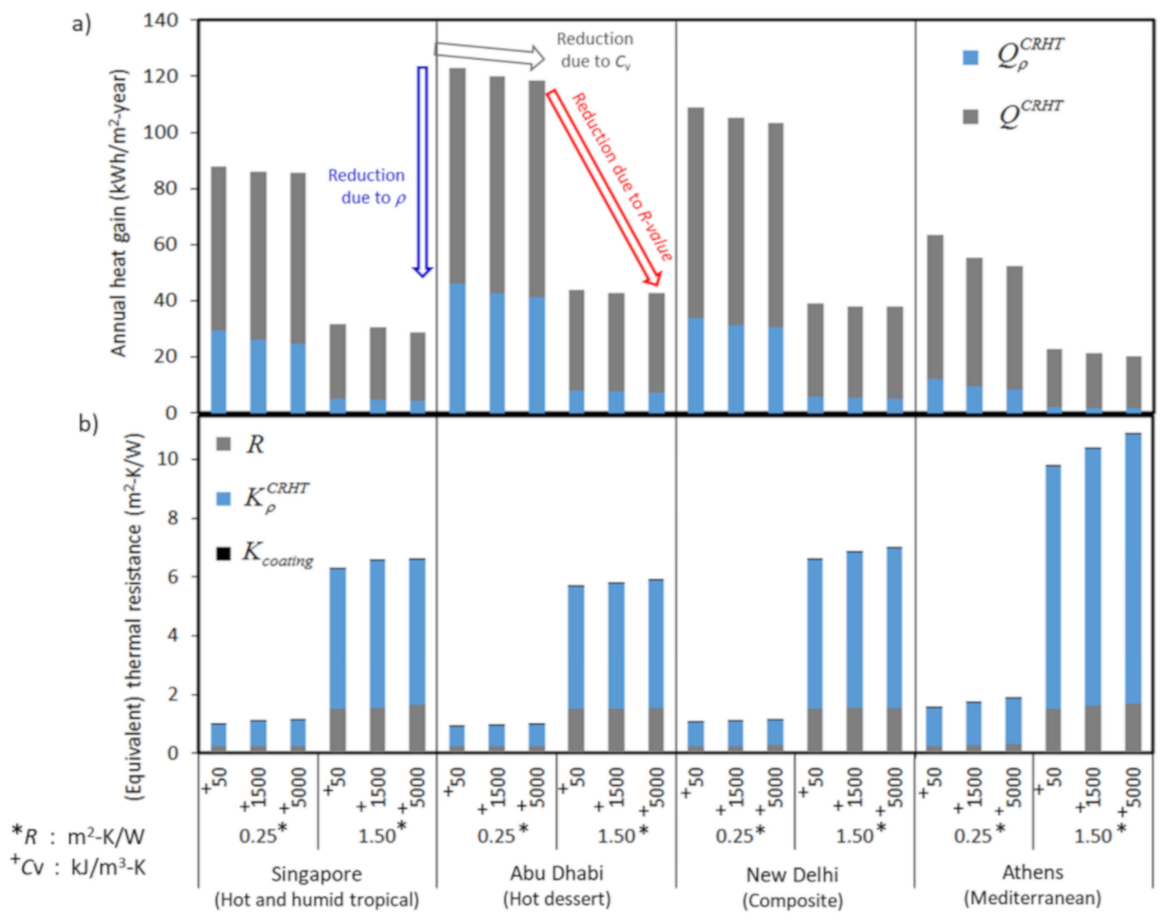

Figure 3. Effects of thermo-physical and solar radiation properties on (a) annual heat gain and (b) $R_{\ell q}$ in different climates ( $Q$ represents the annual heat gain and $K_{\rho}$ and $K_{\text {coating }}$ represents thermal resistance due to both enhanced solar reflectance and cool coating layer).

Table 3. Air film resistance of roof surfaces and weather conditions of selected climates.

\begin{tabular}{|c|c|c|c|c|c|c|}
\hline $\begin{array}{l}\text { Location } \\
\text { (Climate) }\end{array}$ & $\begin{array}{c}\quad \times K_{0} \\
\left(\mathrm{~m}^{2}-\mathrm{K} / \mathrm{W}\right)\end{array}$ & $\begin{array}{c}\quad \times K_{i} \\
\left(\mathrm{~m}^{2}-\mathrm{K} / \mathrm{W}\right)\end{array}$ & $\begin{array}{c}\quad \times \times I_{o} \\
\left(\mathrm{kWh} / \mathrm{m}^{2} \text {-Year }\right)\end{array}$ & $\begin{array}{l}\times T_{o} \\
\left({ }^{\circ} \mathrm{C}\right)\end{array}$ & $\begin{array}{l}\times T_{s k y} \\
\left({ }^{\circ} \mathrm{C}\right)\end{array}$ & $\begin{array}{l}\times \Delta T \\
\left({ }^{\circ} \mathrm{C}\right)\end{array}$ \\
\hline $\begin{array}{c}\text { Singapore } \\
\text { (Hot and humid tropical) }\end{array}$ & 0.031 & 0.234 & 1831 & 27.5 & 18.1 & 5.7 \\
\hline $\begin{array}{c}\text { Abu Dhabi } \\
\text { (Hot dessert) }\end{array}$ & 0.032 & 0.237 & 2896 & 27.1 & 14.9 & 11.9 \\
\hline $\begin{array}{l}\text { New Delhi } \\
\text { (Composite) }\end{array}$ & 0.033 & 0.240 & 2572 & 24.5 & 12.3 & 11.5 \\
\hline $\begin{array}{c}\text { Athens } \\
\text { (Mediterranean) }\end{array}$ & 0.031 & 0.228 & 1938 & 15.7 & 3.7 & 7.4 \\
\hline
\end{tabular}

Increasing $C_{v}$ of the roof section helps to store the heat and delays the heat gain indoors during the daytime. The absorbed heat returns to the sky, when the outdoor air temperature becomes lower than the indoor set point, due to high diurnal temperature variation. The effect of increasing $\rho$ also seems to be more effective in Athens compared to the other three climates for the same reason. The magnitude of annual heat gain through the baseline roof in Athens (Figure 3) is almost 50\% lower and that with a cool roof is almost negligible compared to that of in the three other climates, resulting in a reduction of over $96 \%$ annual heat gain in Athens. It was noticed from Table 3 and Figure 3 that the annual-average sky temperature in Athens is substantially lower (i.e., $3.7^{\circ} \mathrm{C}$ ) than that of the other three climates (in the range of $12.3-18.1^{\circ} \mathrm{C}$ ) resulting in night sky cooling effect.

The combined effect of $R$ and $\rho$ (between $0.25 \mathrm{~m}^{2}-\mathrm{k} / \mathrm{W}$ with $10 \%$ and $1.5 \mathrm{~m}^{2}-\mathrm{k} / \mathrm{W}$ with $80 \%$ ) on annual heat gain reduction varies from 96 to $99 \%$ across all four climates. When the $\rho$ of the roof is 
enhanced from $10 \%$ to $80 \%$, the effect of $R$ on reduction in annual heat gain was only $3 \%$ in the case of Athens compared to the reduction of about $19-24 \%$ in the other three climates. The effect of $R$ in terms of heat gain reduction thus becomes insignificant for a high $\rho$ of the roof in Athens due to its lowest mean outdoor air temperature compared to the other three climates. At the same time, when the $\rho$ of the roof is enhanced to $80 \%$, the heat gain reduction due to the $C_{v}$ effect is observed to be slightly higher $(80 \%)$ in Singapore, compared to $72-76 \%$ in other climates. It is therefore observed that despite having the lowest diurnal temperature variation $\left(5.7^{\circ} \mathrm{C}\right)$, the effect of $C_{v}$ for a high $\rho$ of the roof seems to be more prominent in Singapore due to its mean monthly temperature being higher than the indoor set temperature throughout the year. While comparing the effect of $\rho$ (from 10 to 80\%) between Abu Dhabi and New Delhi, which have similar ambient conditions (Table 3), the annual heat gain reduction is slightly higher in the case of New Delhi due to its lower mean outdoor air temperature.

Among the four climates studied in this paper, the effect of $\mathrm{R}$ (from 0.25 to $1.5 \mathrm{~m}^{2}-\mathrm{k} / \mathrm{W}$ ) in terms of reduction in annual heat gain or increase in equivalent $\mathrm{R}$-value is found to be the highest $(82-83 \%)$ followed by the effect of $\rho$ (from 10 to $80 \%$ ) which is $73-96 \%$ and the effect of $C_{v}$ (from $500 \mathrm{~kJ} / \mathrm{m}^{3} \mathrm{~K}$ to $5000 \mathrm{~kJ} / \mathrm{m}^{3} \mathrm{~K}$ ) which is $2-22 \%$. While comparing the effects between $R$ (from 0.25 to $1.5 \mathrm{~m}^{2}-\mathrm{k} / \mathrm{W}$ ) and $\rho$ (from 10 to $80 \%$ ), the difference in annual heat gain reduction or the equivalent $\mathrm{R}$-value increment, is only about $5-14 \%$ across all the four climates. However, high $R$ materials are usually costlier than cool coating materials by multifold; therefore, a trade-off of the benefits can be performed to arrive at an optimal solution.

\section{Conclusions}

Most of the current building energy regulations/guidelines being implemented across the globe are predominantly developed based on the steady state heat transfer behaviour of building substrate materials and do not highlight the dynamic thermal effect of passive substrate materials. The concept of $R_{e q}$ due to enhanced solar radiation properties (reflectance and emittance) would essentially benefit to understand the effectiveness of applying a cool coating on the outdoor exposed surface of solid roof construction. Numerical models verified against field measurements carried-out at two real-scale unoccupied apartments located on the top floor of a high-rise building in Singapore were used for analysis. The proposed models are generally applicable to any substrate materials properties for different unique climate conditions. It is found that $R_{e q}$, due to enhanced surface reflectance, is dynamic in nature and its contribution is significant in the overall R-value of a roof assembly. In addition, the impact of thermo-physical properties (solar radiation, R-value and volumetric thermal capacity $\left(C_{v}\right)$ ) of substrate material are studied using the proposed models in four cities representing different climate conditions. It is concluded that for a light-weight base case roof with a thermal resistance of (5-mm thick polyurethane) and $C_{v}$ of $500 \mathrm{~kJ} / \mathrm{m}^{3}-\mathrm{K}$, by enhanced $\rho$ alone has benefits during both daytime and nighttime, however increasing R-value or $C_{v}$ alone has benefits only during the day, but not in the night. Among the four different climates studied, the efficiency of cool surface coating and thermal mass was observed to be significant in the Mediterranean climate of Athens (which has dominant colder periods) due to the lowest ambient temperature conditions. However, it could be further concluded that the reduction in annual net heat gain is found to be insignificant with the enhanced thermal mass of substrate construction material.

Author Contributions: Conceptualization, K.T.Z. and M.P.W.; Data curation, K.K.D.E.V.S. and K.T.Z.; writing—original draft preparation, K.K.D.E.V.S., Formal analysis, K.T.Z., K.K.D.E.V.S and M.P.W., writing一review and editing, M.P.W.; funding acquisition, M.P.W. All authors have read and agreed to the published version of the manuscript.

Funding: This project is supported by the Housing \& Development Board, Singapore. Technical and logistical support by Energy Research Institute at NTU (ERI@N) and the Hong Kong Research Grant Council via Collaborative Research Fund (CRF) account C6022-16G are gratefully acknowledged.

Conflicts of Interest: The authors declare no conflict of interest. 


\section{References}

1. Al-Sanea, S.A.; Zedan, M.F.; Al-Hussain, S.N. Effect of masonry material and surface absorptivity on critical thermal mass in insulated building walls. Appl. Energy 2013, 102, 1063-1070. [CrossRef]

2. Zingre, K.T.; Wan, M.P.; Tong, S.; Li, H.; Chang, V.W.-C.; Wong, S.K.; Toh, W.B.T.; Lee, I.Y.L. Modeling of cool roof heat transfer in tropical climate. Renew. Energy 2015, 75, 210-223. [CrossRef]

3. Zingre, K.T.; Yang, X.; Wan, M.P. Performance Analysis of Cool Roof, Green Roof and Thermal Insulation on a Concrete Flat Roof in Tropical Climate. Evergreen 2015, 2, 34-43. [CrossRef]

4. Ramakrishnan, S.; Wang, X.; Sanjayan, J.; Wilson, J. Thermal performance assessment of phase change material integrated cementitious composites in buildings: Experimental and numerical approach. Appl. Energy 2017, 207, 654-664. [CrossRef]

5. Alam, M.; Zou, P.X.; Sanjayan, J.; Ramakrishnan, S. Energy saving performance assessment and lessons learned from the operation of an active phase change materials system in a multi-storey building in Melbourne. Appl. Energy 2019, 238, 1582-1595. [CrossRef]

6. Nazir, H.; Batool, M.; Osorio, F.J.B.; Isaza-Ruiz, M.; Xu, X.; Vignarooban, K.; Phelan, P.; Inamuddin; Kannan, A.M. Recent developments in phase change materials for energy storage applications: A review. Int. J. Heat Mass Transf. 2019, 129, 491-523. [CrossRef]

7. Ramakrishnan, S.; Wang, X.; Sanjayan, J.; Wilson, J. Thermal performance of buildings integrated with phase change materials to reduce heat stress risks during extreme heatwave events. Appl. Energy 2017, 194, 410-421. [CrossRef]

8. Lei, J.; Kumarasamy, K.; Zingre, K.T.; Yang, J.; Wan, M.P.; Yang, E.-H. Cool colored coating and phase change materials as complementary cooling strategies for building cooling load reduction in tropics. Appl. Energy 2017, 190, 57-63. [CrossRef]

9. Zingre, K.T.; Yang, E.H.; Wan, M.P. Dynamic thermal perfomance of inclined double-skin roof: Modeling and experimental investigation. Energy 2017, 133, 900-912. [CrossRef]

10. Kumar, D.K.; Puranik, S. Thermal performance evaluation of a mineral-based cement tile as roofing material. Indoor Built Environ. 2016, 26, 409-421. [CrossRef]

11. Kosny, J.; Christian, J.E.; Desjarlais, A.O.; Kossecka, E.; Berrenberg, L. The performance check between whole building thermal performance criteria and exterior wall; Measured clear wall R-value, thermal bridging, thermal bass, and air- $\backslash$ tightness. ASHRAE Transactions 1998, 104.

12. Long, L.; Ye, H. The roles of thermal insulation and heat storage in the energy performance of the wall materials: A simulation study. Sci. Rep. 2016, 6, 24181. [CrossRef] [PubMed]

13. Muscio, A.; Akbari, H. An index for the overall performance of opaque building elements subjected to solar radiation. Energy Build. 2017, 157, 184-194. [CrossRef]

14. Zingre, K.T.; Wan, M.P.; Yang, X. A new RTTV (Roof thermal transfer value) model for cool roofs. Energy 2015, 81, 222-232. [CrossRef]

15. Zingre, K.T.; Wan, M.P.; Wong, S.K.; Toh, W.B.T.; Lee, I.Y.L. Modelling of cool roof performance for double-skin roofs in tropical climate. Energy 2015, 82, 813-826. [CrossRef]

16. EnergyPlus Weather Dataset. Typical Meteorological Year Weather Data Files for EnergyPlus Simulations, U.S; Department of Energy, University of Illinois: Chicago, IL, USA, 2013.

17. Tong, S.; Li, H.; Zingre, K.T.; Wan, M.P.; Chang, V.W.-C.; Wong, S.K.; Toh, W.B.T.; Lee, I.Y.L. Thermal performance of concrete-based roofs in tropical climate. Energy Build. 2014, 76, 392-401. [CrossRef]

(C) 2020 by the authors. Licensee MDPI, Basel, Switzerland. This article is an open access article distributed under the terms and conditions of the Creative Commons Attribution (CC BY) license (http://creativecommons.org/licenses/by/4.0/). 